\title{
The use of conventional electromyography to assess external sphincter neuropathy in man
}

\author{
DCC BARTOLO, JA JARRATT, NW READ \\ From the Departments of Surgery, Physiology and Clinical Neurophysiology, University of Sheffield, \\ Sheffield, $U K$
}

SUMMARY Conventional electromyography was used to measure motor unit potential duration in the external anal sphincter in normal subjects and patients with idiopathic faecal incontinence. The results revealed a direct correlation between age and mean motor unit potential duration in control subjects, but no differences between age-matched male and female subjects. Patients with faecal incontinence exhibited prolongation of mean motor unit potential duration compared with matched controls. This technique provided useful quantitative data on reinnervation within the anal sphincter, complementing the results of single fibre electromyography.

Recent work has indicated that most patients with idiopathic faecal incontinence have denervation of the external anal sphincter. ${ }^{1-4}$ This conclusion is based on histological examination of muscle specimens, taken at operation, ${ }^{12}$ and on single fibre electromyography (SFEMG). ${ }^{34}$ Conventional electromyography has been used previously to record motor unit potentials from normal anal sphincters and to demonstrate some of the qualitative abnormalities that may be found in neuropathic sphincter muscle. ${ }^{5-8}$ This technique was applied in a systematic quantitative manner to study motor nerve regeneration within the anal sphincter.

\section{Material and methods}

\section{Subjects}

Recordings were taken from 18 patients (17 female, one male; aged 38 to 93 years, mean $=69$ years) and 20 normal controls (eight males, 12 females; aged 20 to 80 years, mean age 56 years). The controls were hospital patients with disorders not affecting the gastrointestinal or nervous systems. Informed consent was obtained in all cases, and the study was approved by the Ethical Committee of the Sheffield Area Health Authority. Each examination lasted about half an hour and was well tolerated.

Address for reprint requests: Dr NW Read, Clinical Research Unit, Floor H, Royal Hallamshire Hospital, Sheffield S10 2JG, UK.

Received 3 February 1983 and in revised form 11 June 1983. Accepted 28 June 1983

\section{Recording technique}

With the patient lying in the left lateral position, a conventional concentric needle electrode (Type 13L49; Disa, Copenhagen) was inserted without anaesthetic into the external anal sphincter. A metal ground electrode was placed on the skin of the natal cleft close to the anal margin. Standard EMG apparatus (Type MES; Medelec, Woking) was used to amplify and display the potentials recorded. The settings of the amplifier (Type AA6 MK IIM; Medelec, Woking) were as follows: gain at $200 \mu \mathrm{V} /$ cm or $500 \mu \mathrm{V} / \mathrm{cm}$, low frequency filter at $16 \mathrm{~Hz}$, high frequency filter at $3200 \mathrm{~Hz}$. A time base of 5 or $10 \mathrm{~ms} / \mathrm{cm}$ was used. Trigger and delay facilities (Type SD6; Medelec, Woking) enabled individual motor unit potentials to be identified and the stability of their components to be assessed. Films of the potentials were taken on light sensitive paper (Linagraph Type 1895; Kodak) from which measurements of motor unit potential durations were made. The EMG signals were also stored on an FM tape recorder (Type 7758A; Hewlett Packard, Waltham, Mass) for further analysis as required.

The "tonic" activity of the sphincter at rest provided sufficient activity for analysis. Recordings were obtained from both lateral margins of the external anal sphincter. The duration of each motor unit potential was taken as the time interval from the departure of the sweep from the baseline at the onset of the potential to the return of the sweep to the baseline after the last component of the potential.

Statistical methods and data analysis

At least twenty motor units were measured in each subject, and from these the mean motor unit potential duration (MUPD) was calculated for each subject. For analysis the subjects in each group were matched with regard to their ages and the difference in mean MUPD between the incon- 


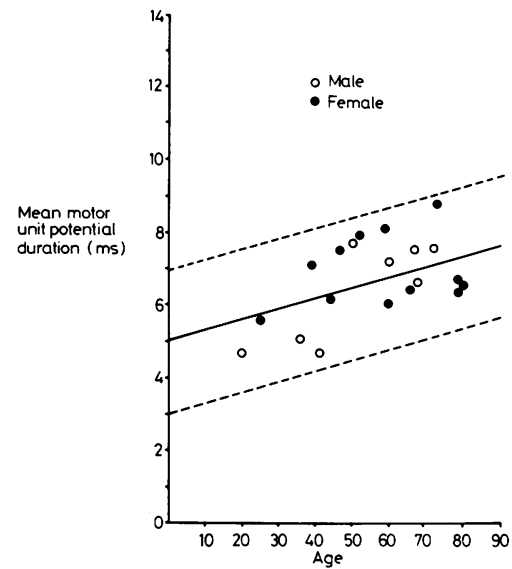

Fig 1 The relationship between mean motor unit potential duration and age in 20 normal subjects showing a significant increase in MUPD with age $(r=0.49 ; p<0.05)$.

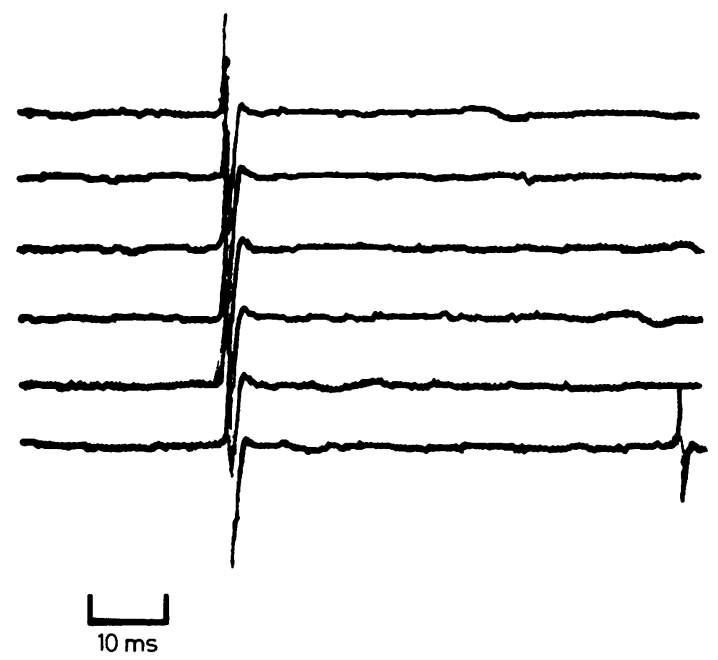

Fig 2 An example of a motor unit potential of short duration.

tinent and control groups was assessed by both parametric and non-parametric methods. The statistical significance of the differences between age-matched subjects in the incontinent and control groups, quoted in the results, applies to both methods of statistical analysis.

\section{Results}

Effect of age and sex

There was a significant direct correlation between age and mean MUPD in control subjects $(r=0.49$; $\mathrm{p}<0.05$ ) (fig 1 ). No such age correlation was

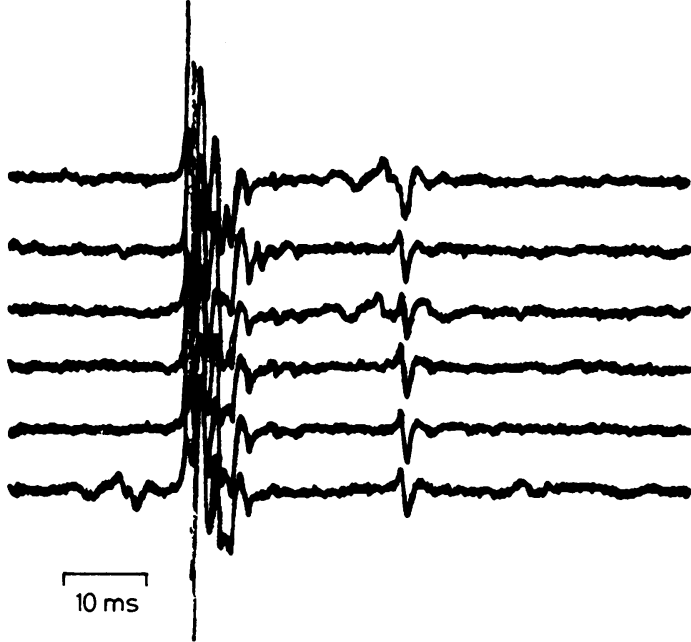

Fig 3 An example of a motor unit potential of long duration.

observed in incontinent patients. There were no significant differences in mean MUPD between age-matched male and female control or incontinent subjects.

\section{Comparison of control and incontinent subjects}

Motor units of widely differing sizes were seen; figs 2 and 3 show examples of short and long duration potentials respectively. Although the range of motor unit potential durations was large in both groups (fig 4), the longer duration potentials were more commonly seen in the incontinent patients (percentage of motor units above $10 \mathrm{~ms}$ : control $12 \%$, incontinent patients $36 \%$; $<<0.001$ ). The mean MUPDs were also significantly longer in incontinent patients $(9.3 \pm 0.2 \mathrm{~ms}$; mean $\pm \mathrm{SEM})$, compared with control subjects $(6.9 \pm 0.3 \mathrm{~ms} ; \mathrm{p}<0.001)$ (fig 5). Prominent jitter and blocking were often seen in the records from the incontinent group (fig 6), though no attempt was made to quantitate these observations.

\section{Discussion}

The value of conventional EMG in diagnosing neurogenic change in skeletal muscle is wellestablished. ${ }^{10}$ More recently, SFEMG has been used to detect neurogenic change in the external anal sphincter. ${ }^{34}$ We have found that it is perfectly feasible to use conventional electromyographic techniques for the same purpose and our results, showing prolonged MUPDs in incontinent patients, correspond with single fibre recordings, showing 
The use of conventional electromyography to assess external sphincter neuropathy in man

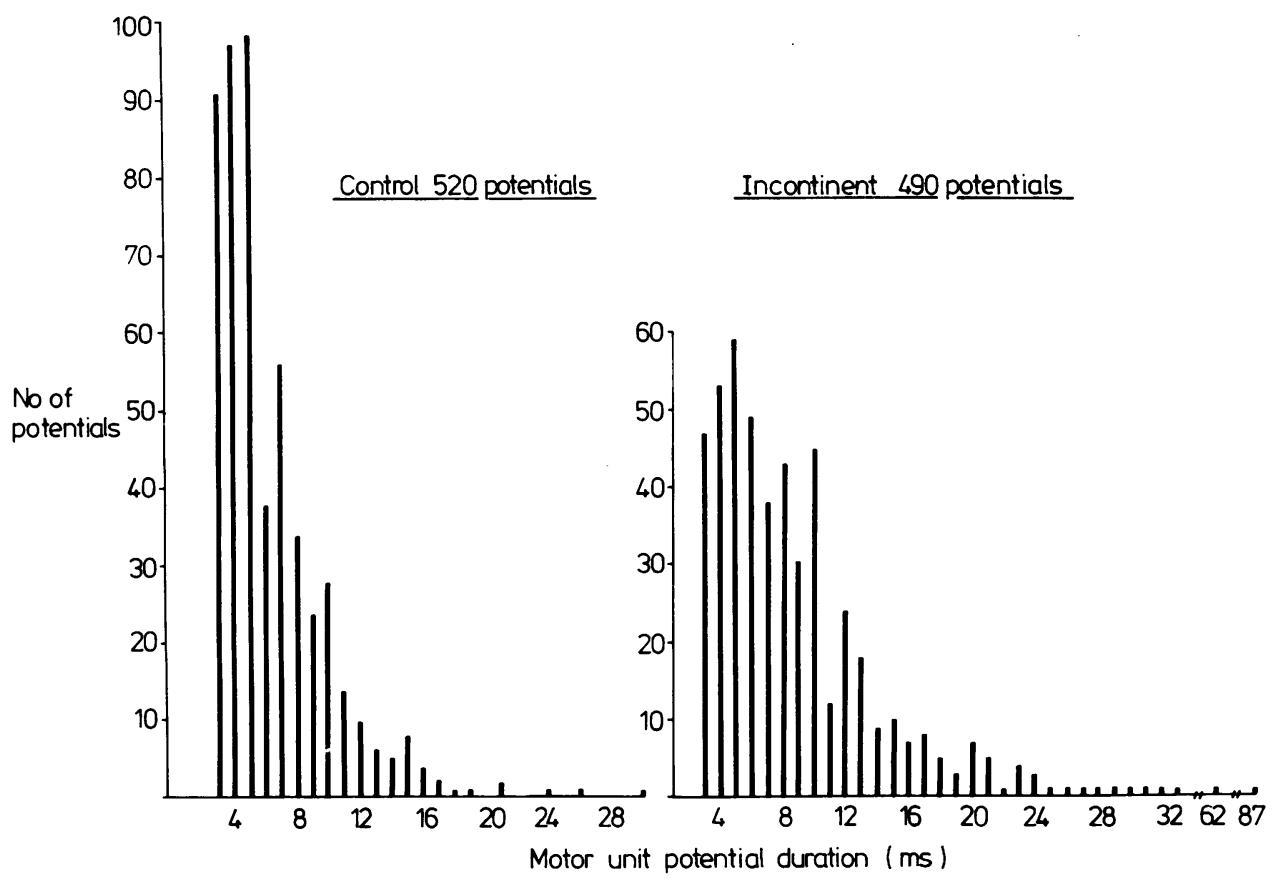

Fig 4 A histogram of the pooled motor unit potentials from the two groups, showing the distribution of motor unit potential durations in normal controls and in incontinent patients.

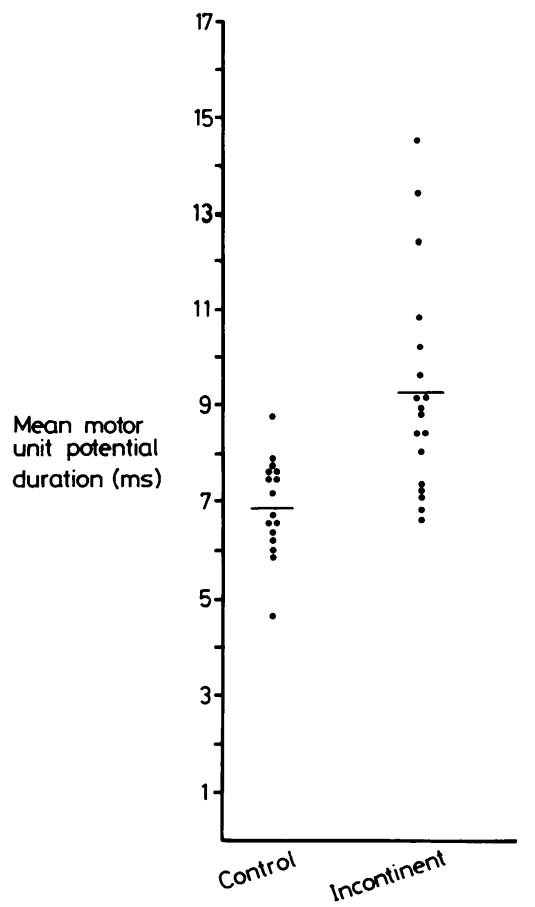

Fig 5 Comparison of the age matched mean motor unit potential durations from 16 controls and 18 patients with faecal incontinence.

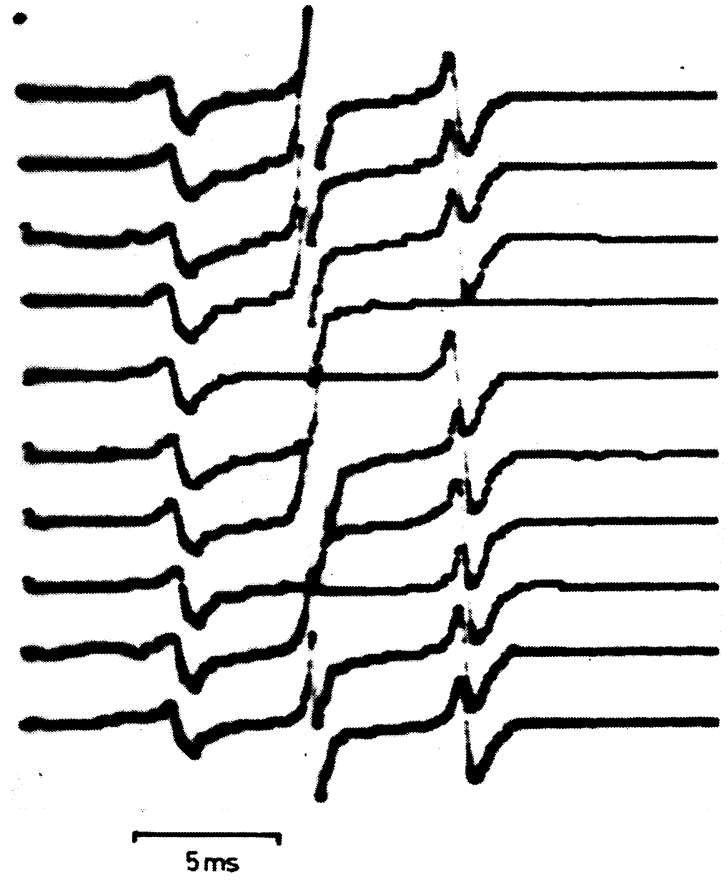

Fig 6 Consecutive discharges of a motor unit potential, showing jitter and intermittent blocking of the second and third components. 
increased fibre density. ${ }^{34}$ Thus either technique can be used to demonstrate motor nerve regeneration in the external anal sphincter of incontinent patients. We have also used conventional EMG to diagnose neurogenic change in puborectalis. ${ }^{11}$

The reason why the mean MUPD that we measured in normal controls was greater than in earlier studies, ${ }^{5-7}$ can be explained by the advantages of trigger and delay facilities, which allow easier and more accurate measurement of MUPD, and in particular the recognition of late components.

There is abundant electrophysiological evidence to show that the incidence of neuropathic change in skeletal muscle increases with age. ${ }^{11}$ A similar relationship in the case of the external anal sphincter muscle has been demonstrated using SFEMG ${ }^{12}$ and confirmed in our study using conventional EMG. This correlation would explain the reduction in sphincter pressure that occurs with age. ${ }^{13}$ It is not known whether this change is simply due to the effects of ageing of the nerve supply to striated muscle in general $^{914}$ or whether it is exacerbated by stretch injury to the pudendal nerve, produced by long term straining at stool.

Although SFEMG is the method of choice for recording jitter and blocking, the finding of prominent jitter and blocking by conventional EMG techniques in incontinent patients implies recent and perhaps continuing nerve injury. ${ }^{1516}$ This observation would indicate that the pudendal nerves are being continuously subjected to damage, possibly by straining at stool, ${ }^{\prime}$ and would be against the possibility that neuropathy in patients with idiopathic faecal incontinence is due to a single traumatic event, occurring, for example, during childbirth.

The study was supported by grants from the Trent Regional Health Authority and the Sheffield Area Health Authority. The authors gratefully acknowledge the advice and encouragement of Professor Alan Johnson, Head of the Surgical Unit.

\section{References}

' Parks AG, Swash M, Urich H. Sphincter denervation in anorectal incontinence and rectal prolapse. Gut 1977; 18:656-65.

${ }^{2}$ Beersiek F, Parks AG, Swash M. Pathogenesis of anorectal incontinence: a histometric study of the anal canal musculature. J Neurol Sci 1979;42:111-27.
${ }^{3}$ Neill ME, Parks AG, Swash M. Physiological studies of the anal sphincter musculature in faecal incontinence and rectal prolapse. Br J Surg 1981;68:531-6.

${ }^{4}$ Neill ME, Swash M. Increased motor unit fibre density in the external anal sphincter in ano-rectal incontinence: a single fibre EMG study. J Neurol Neurosurg Psychiatry 1980;43:343-7.

${ }^{5}$ Chantraine A. EMG examination of the anal and urethral sphincters. In: Desmedt JE, ed. New Developments in Electromyography and Clinical Neurophysiology Basle: Karger, 1973;2:421-32.

${ }^{6}$ Chantraine A. Electromyographie des sphincters stries uretal et anal humains. Etude descriptive et analytique. Rev Neurol (Paris) 1966;115:396-403.

7 Jesel M, Isch-Treussard C, Isch F. Electromyography of striated muscle of anal and urethral sphincters. In: Desmedt JE. ed. New Developments in Electromyography and Clinical Neurophysiology Vol. 2. Basle: Karger, 1973:406-20.

${ }^{8}$ Kerremans R. Morphological and Physiological Aspects of Anal Incontinence and Defaecation. Brussels: Ed. Arsica, SA, 1969.

${ }^{9}$ Buchthal F, Pinelli, P. Action potentials in muscular atrophy of neurogenic origin. Neurology (Minneap) 1953:3:591-603.

${ }^{10}$ Sacco G, Buchthal F, Rosenfalk P. Motor unit potentials at different ages. Arch Neurol 1962;6:366-73.

" Bartolo DCC, Jarratt JA, Read MG, Donnelly TC, Read NW. The role of partial denervation of the puborectalis in idiopathic faecal incontinence. Br J Surg 1983; (in press).

12 Rosenfalck P. Electromyography in Normal Subjects of Different Age. Published by the Laboratory of Clinica Neurophysiology, Rigshospitalet, Copenhagen, 1975; $1-49$.

${ }^{13}$ Percy JP, Neill ME, Kandiah TK, Swash M. A neurogenic factor in faecal incontinence in the elderly. Age Ageing 1982;11:175-9.

${ }^{14}$ Read NW, Harford WV, Schmulen AC, Read MG, Santa AC, Fordtran JS. A clinical study of patients with faecal incontinence and diarrhoea. Gastroenterology 1979;76:747-56.

15 Tomlinson BE, Walton JN, Rebeiz JJ. The effects of aging and cachexia upon skeletal muscle. A histopathological study. J Neurol Sci 1969;9:321-46.

${ }^{16}$ Stalberg E, Ekstedt J. Single fibre EMG and microphysiology of the motor unit in normal and diseased human muscle. In: Desmedt JE, ed: New Developments in Electromyography and Clinical Neurophysiology. Basel. Karger 1973;1:113-29.

${ }^{17}$ Stalberg E, Thiele B. Transmission block in terminal nerve twigs: A single fibre electromyographic finding in man.J Neurol Neurosurg Psychiatry 1972:35:52-9. 